\title{
Educação musical em Barra Mansa (RJ): o perfil dos alunos de dois grupos sinfônicos do projeto Música nas Escolas
}

Nilton Soares da Silva Júnior

Mestre em Música pela Universidade Federal do Rio de Janeiro - UFRJ Doutorando em Música pela Universidade Federal do Rio de Janeiro - UFRJ

Regente e professor do Centro Universitário de Barra Mansa - UBM 


\section{Resumo}

Este artigo pretende traçar o perfil dos alunos participantes de dois grupos sinfônicos do Projeto Música nas Escolas de Barra Mansa: a Banda Sinfônica e a Orquestra Sinfônica Juvenis de Barra Mansa. Partindo de um questionário, procuramos coletar informações como escolaridade, onde se iniciaram na música, o tempo de estudo, dentre outras questões.

Palavras-chave: Conjuntos Musicais. Ensino de Música. Banda Juvenil. Orquestra Juvenil. Apreciação Musical.

\section{Abstract}

In this article, we aim to study the profile of students enrolled to both symphonic ensembles of the Musica nas Escolas de Barra Mansa Project: the Symphonic Band and the Youth Symphonic Orchestra of Barra Mansa. By the means of a survey, we assessed data such as, among others, education level, how did they their musical studies, and total length of musical studies.

Keywords: Musical Ensembles. Musical Teaching. Youth Band. Youth Orchestra. Musical Listening. 


\section{Introdução}

O Projeto Música nas Escolas de Barra Mansa (P.M.E.B.M.) teve início em 2003, a partir da reformulação de uma banda de metais formada por alunos da rede pública municipal. O objetivo inicial, foi a implantação de um modelo de educação voltado para prática instrumental.

A partir da reformulação e implantação de aulas de outros instrumentos musicais, o P.M.E.B.M. passou a oferecer nas escolas da rede pública, a partir da educação infantil, a aplicação de um programa de musicalização, que continua até o quinto ano do ensino fundamental. A partir do sexto ano, é desenvolvido um programa de apreciação musical e história da música universal e, da música brasileira. Já a prática instrumental, tem início no terceiro ano do ensino fundamental.

No momento inicial, o projeto já contava com 600 alunos. Atualmente, cerca de 22.500 alunos são contemplados com o ensino de música. Com a ampliação das vagas, surgiram vários conjuntos sinfônicos, populares e de câmara.

O processo, permitiu a criação de inúmeros conjuntos com alunos, monitores e professores do projeto: (a) Orquestra Sinfônica de Barra Mansa; (b) Banda Sinfônica de Barra Mansa; (c) Orquestra de Metais; (d) Orquestra de Percussão; (e) Orquestra Sinfônica Juvenil; (f) Banda Sinfônica Juvenil; (g) 03 Bandas de Música infantis; (h) Orquestra de Jazz; (i) Grupo de Percussão Brasileira; (j) 08 Grupos de Percussão com instrumentos reciclados; $(\mathrm{k}) 52$ corais infantis nas unidades escolares; e (1) 50 Grupos de Pífaro. Os alunos de prática instrumental têm atividades divididas em: (a) aulas individuais de instrumento; (b) aulas de prática coletiva; (c) teoria musical; (d) música de câmara; e (e) prática de banda e orquestra. A Orquestra Sinfônica de Barra Mansa permite a integração entre monitores e alunos avançados e desenvolve repertório sinfônico de alta performance, com uma excelente temporada anual. Os demais grupos se dividem em concertos e apresentações, incluindo os concertos didáticos, que circulam pelas escolas da cidade. Em média, o processo de circulação permite 230 concertos e apresentações por ano (ALVARES et. al. 2015, p.2)

No momento inicial, o projeto já contava com 600 alunos. Atualmente, cerca de 22.500 alunos são contemplados com o ensino de música. Com o aumento do número de alunos, Alvares (2015) cita os vários conjuntos sinfônicos, populares e de câmara surgiram, a partir do projeto. 
Por tratar-se de um projeto bastante extenso, delimitamos a pesquisa a dois grupos, a Banda Sinfônica e a Orquestra Sinfônica Juvenis de Barra Mansa. Portanto, o objetivo deste artigo é traçar um perfil musical dos alunos que fazem parte destes dois grupos.

Através de um questionário fechado, procuramos identificar fatos como escolaridade, motivação para o estudo de música, se há algum músico na família, o tempo de estudo, onde iniciaram os estudos e quais são os gêneros musicais preferidos destes alunos, uma vez que tanto a banda como a orquestra procuram manter em seu repertório músicas dos mais diversos gêneros gênero.

As questões respondidas, foram:

(a) Escolaridade e ocupação.

(b) O que te motivou a estudar Música?

(c) Há algum músico na família?

(d) A quanto tempo estuda música?

(e) Onde você começou a estudar música?

(f) Você ouve música frequentemente? Quais os gêneros musicais você mais gosta de ouvir?

Segundo informações do sítio na internet do P.M.E.B.M., a Banda Sinfônica Juvenil

É um dos grupos do Projeto Música nas Escolas, e formada por alunos dos polos de metais, madeiras e percussão. Iniciado em 2007, o grupo recebe alunos das escolas municipais e da rede estadual, estudantes a partir do $6^{\circ}$ ano do ensino fundamental. A Banda Sinfônica Juvenil realiza concertos em Barra Mansa, cidades vizinhas e se apresenta nos bairros em uma série de concertos didático-populares, contribuindo para o crescimento da cultura musical no município e na região sulfluminense ${ }^{1}$.

Com relação à Orquestra Sinfônica Juvenil, o mesmo sítio informa que a iniciativa de criação do conjunto partiu da necessidade de preparar alunos para a Orquestra Sinfônica de Barra Mansa (OSBM).

\footnotetext{
${ }^{1}$ http://www.musicanasescolas.com/grupos/banda_sinfonica/juvenil/index.php Acesso em 11 de abril. de 1017.
} 
Desta forma, surgiu a OSBM Juvenil, formada pelos músicos mais novos, que se preparam para atuarem também, na Orquestra Sinfônica de Barra Mansa. Os músicos da Orquestra Sinfônica Juvenil são alunos dos polos de prática instrumental do Projeto Música nas Escolas, com faixa etária de 10 a 18 anos e alunos do Ensino Fundamental e do Ensino Médio. Durante a semana, os alunos estudam nestes polos, que são divididos de acordo com o tipo de instrumento: percussão, cordas, metais e madeiras. Nos dias de prática de conjunto, os alunos ensaiam na sede do Projeto, localizada no Parque da Cidade. A Orquestra Sinfônica Juvenil é composta por 80 músicos entre alunos e bolsistas do Projeto Música nas Escolas, sendo sua composição semelhante à da OSBM. Desde sua formação, a OSBM Juvenil realizou concertos em diversas cidades e eventos de música².

A Orquestra Sinfônica de Barra Mansa, principal conjunto surgido no seio do projeto, é formada por professores e bolsistas advindos da banda, e também da orquestra.

\section{Perfil dos Alunos}

Combinado previamente com os maestros, parte do ensaio foi cedido gentilmente para que pudéssemos aplicar o questionário. No dia estavam presentes vinte e oito alunos da orquestra, por tratar-se de ensaio de cordas, e da banda, quarenta e dois. Os ensaios acontecem nos mesmos dias da semana, quartas e sextasfeiras, sendo que o ensaio da orquestra se inicia às $18 \mathrm{~h} 30$ e vai até as $20 \mathrm{~h} 30$, e o ensaio da banda das 19 h00 às $20 \mathrm{~h} 30$.

A faixa etária dos alunos da banda é entre 10 e 18 anos, sendo a média dos 12 aos 15 anos. Já a orquestra, a faixa etária vai de 13 aos 23 anos, com uma média entre 15 e 17 anos.

\footnotetext{
${ }^{2}$ http://www.musicanasescolas.com/grupos/orquestra_sinfonica/index.php acesso em 11 de abr. 2017
} 


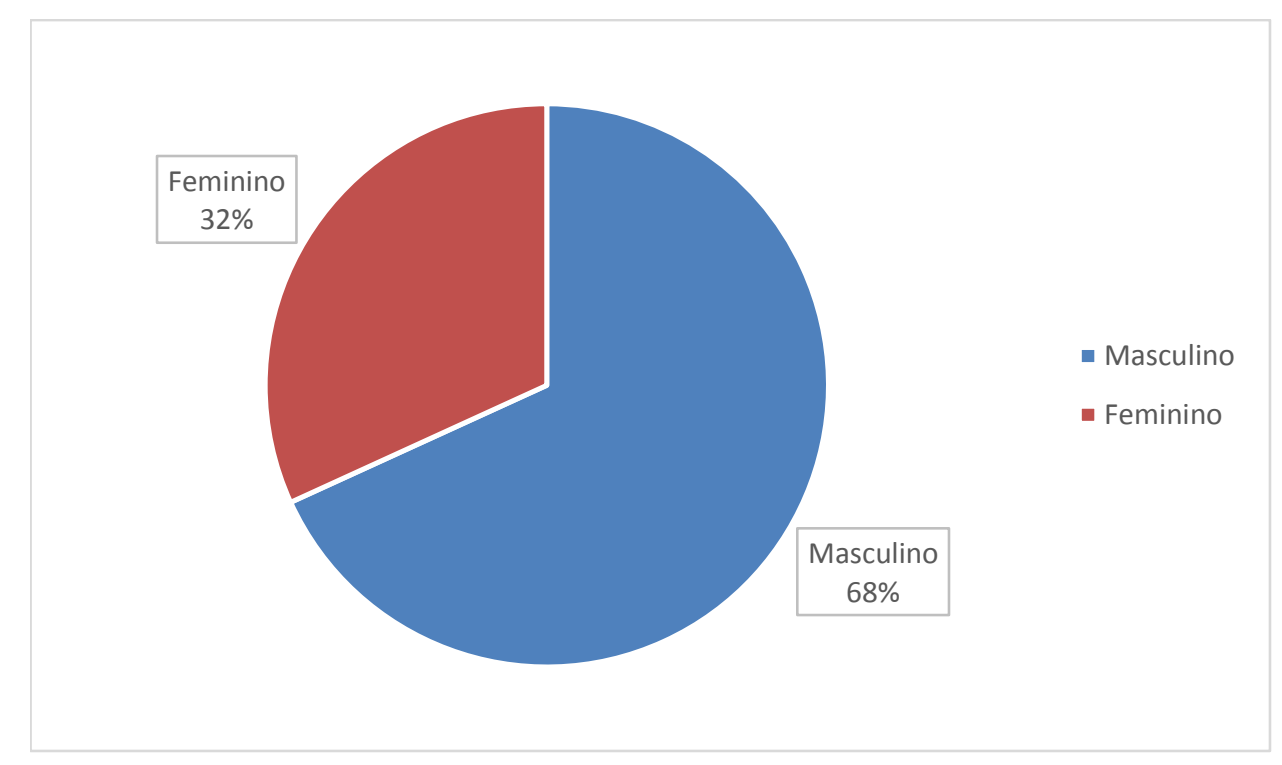

Gráfico 1- Banda Sinfônica Juvenil - Gênero

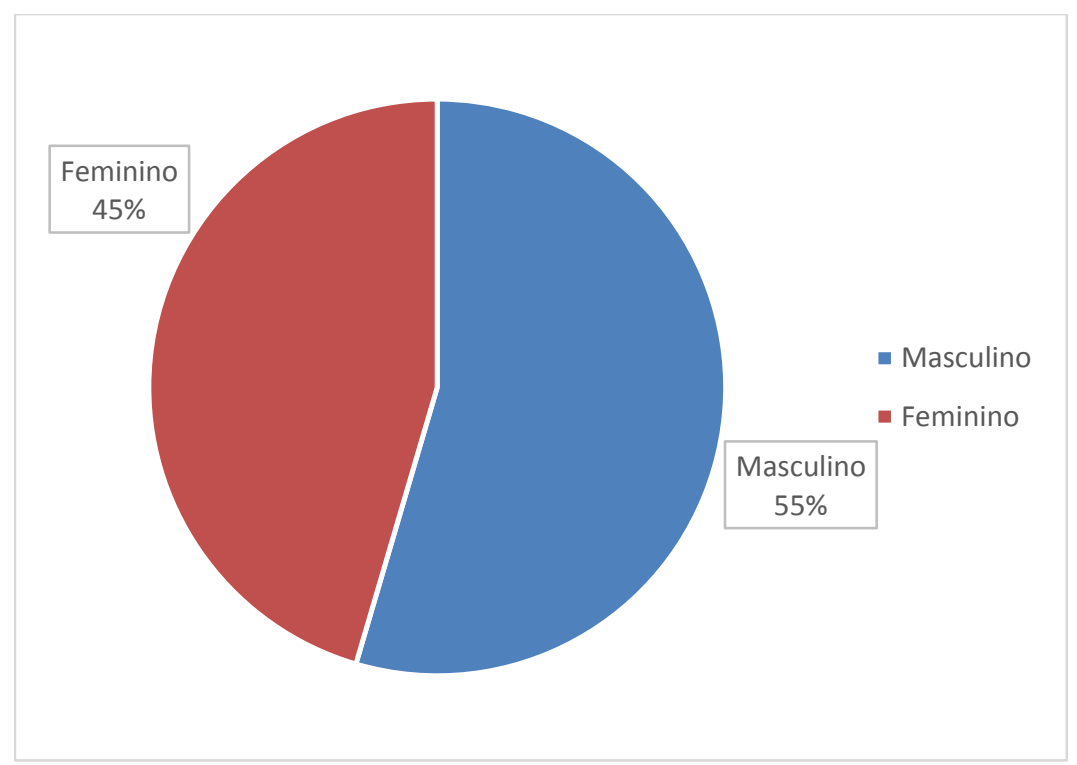

Gráfico 2 - Orquestra Sinfônica Juvenil - Gênero

Em se tratando de gênero, tanto a banda quanto a orquestra têm em seus quadros a maioria masculina. Na banda, 68\% músicos são alunos do sexo masculino, e $32 \%$, do sexo feminino. Na orquestra, os alunos do sexo masculino são $55 \%$, e do sexo feminino, $45 \%$ do total. 


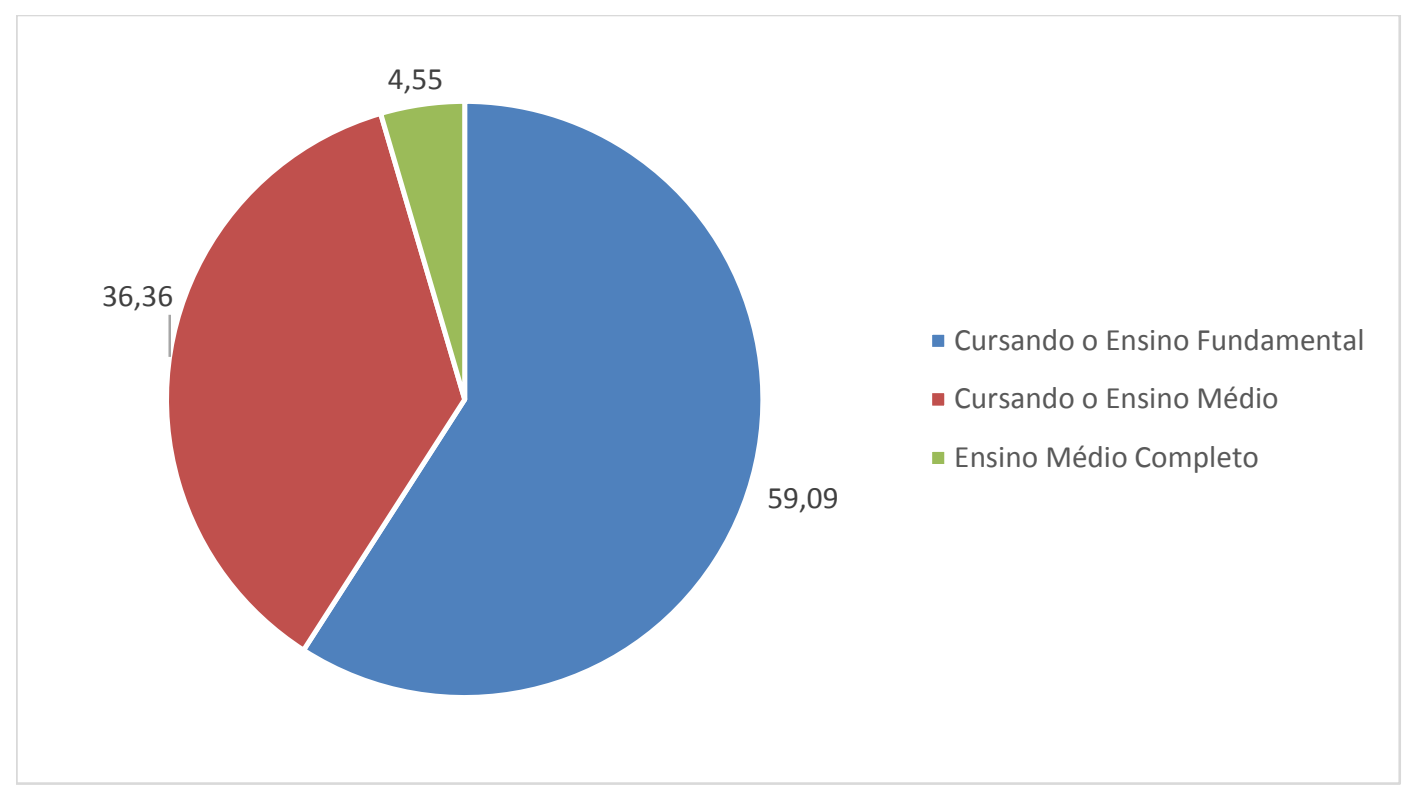

Gráfico 3 - Banda Sinfônica Juvenil - Escolaridade

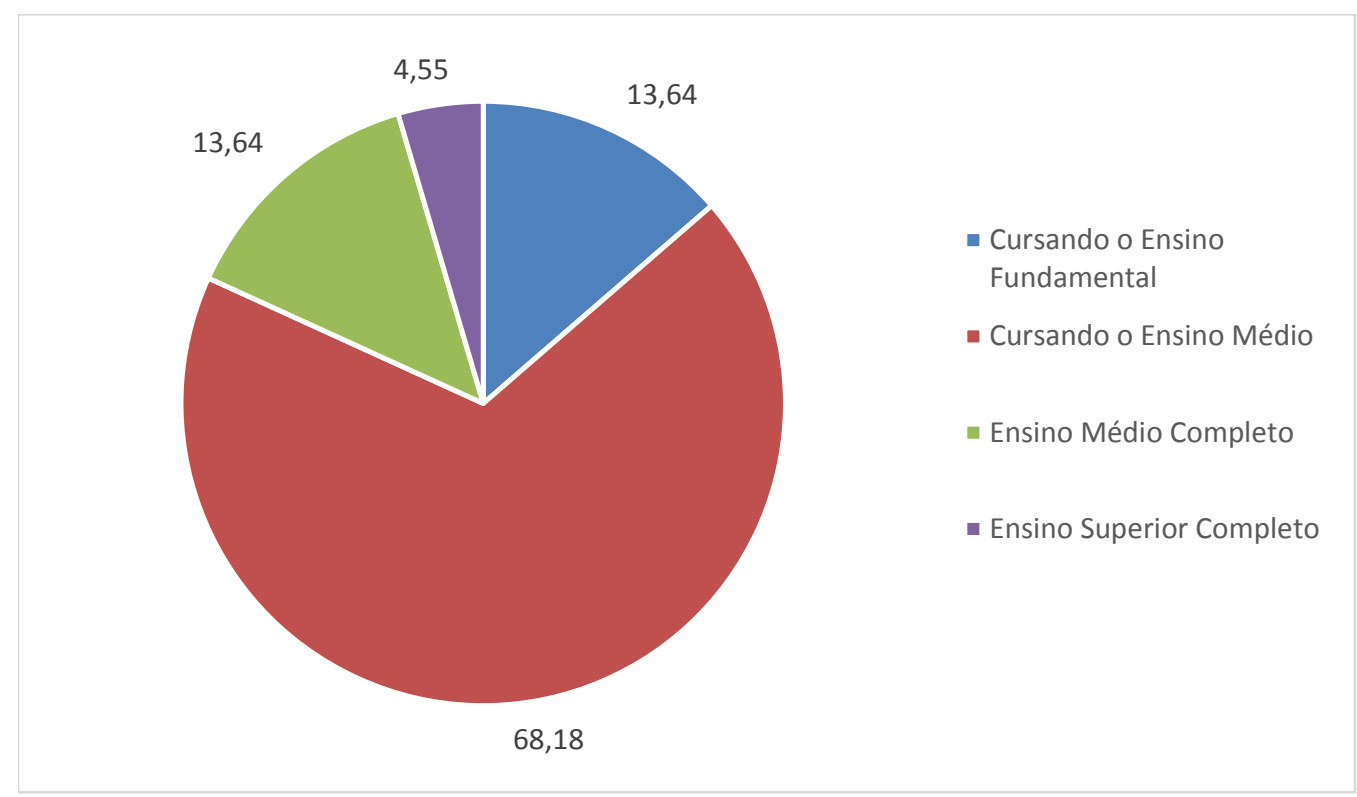

Gráfico 4 - Orquestra Sinfônica Juvenil - Escolaridade

Com relação à escolaridade, na banda 59,09\% estão cursando o ensino fundamental, 36,36\% cursando e 4,55\% já terminaram o ensino médio. Na orquestra, $13,64 \%$ cursam o ensino fundamental, $68,18 \%$ o ensino médio, $13,64 \%$ tem o ensino médio completo e, $4,55 \%$, possui curso superior completo.

Perguntados sobre a ocupação na banda, com exceção de um aluno que se declarou professor de inglês, todos os outros são estudantes. $\mathrm{Na}$ orquestra, uma 
componente é professora, e outro aluno, auxiliar de construção civil. Todos os demais, estudantes. Nos dois grupos, alguns são bolsistas, e desempenhado funções de monitoria na Banda C e na Orquestra Suzuki, grupos de iniciação musical.

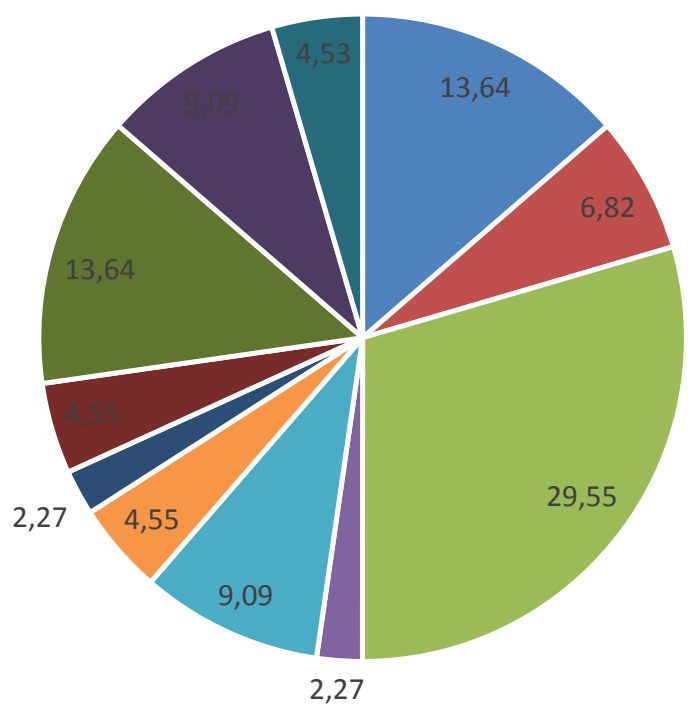

- Familiares músicos

- Assistir aos músicos na igreja

- Gosto pessoal

- Indicação médica - problema de saúde Por gostar de ouvir música

- Convite de um amigo

- Não sabe

- A felicidade que a música traz

- Um concerto ou apresentação assistido

- Sonho de tocar um instrumento

- Incentivo do pai

Gráfico 5- Motivação para o estudo de música

Sobre o fator motivador que os levou a estudar música, 29,55\% dos alunos disseram que foi o gosto pela própria música. Em seguida, 13,64\% sentiu-se influenciado por um concerto ou apresentação assistidos. Dentro deste ponto, vale ressaltar que as apresentações a que se referem, foram a de professores do P.M.E.B.M em suas próprias escolas, em concertos didáticos, ou em concertos da Orquestra ou da Banda Sinfônicas, grupos com temporada regular de concertos. Outros 13,64\%, sentiram-se motivados por um familiar músico. Dentre outros motivos, 9,09\%, disse que foi o gosto de ouvir música; 9,09\%, sonho de tocar um instrumento; 6,82\%, assistir aos músicos da igreja; 4,55\%, convite de um amigo; 4,55\% a felicidade que a música traz; $4,55 \%$, incentivo do pai; $2,27 \%$, indicação médica por motivo de saúde, que no caso foi uma bronquite. Outro 2,27\% não responderam. 

nas Escolas. R. Cientifica UBM - Barra Mansa (RJ), ano XXII, v. 19, n. 37, 2. Sem. 2017. p. 123-139.

ISSN 1516-4071

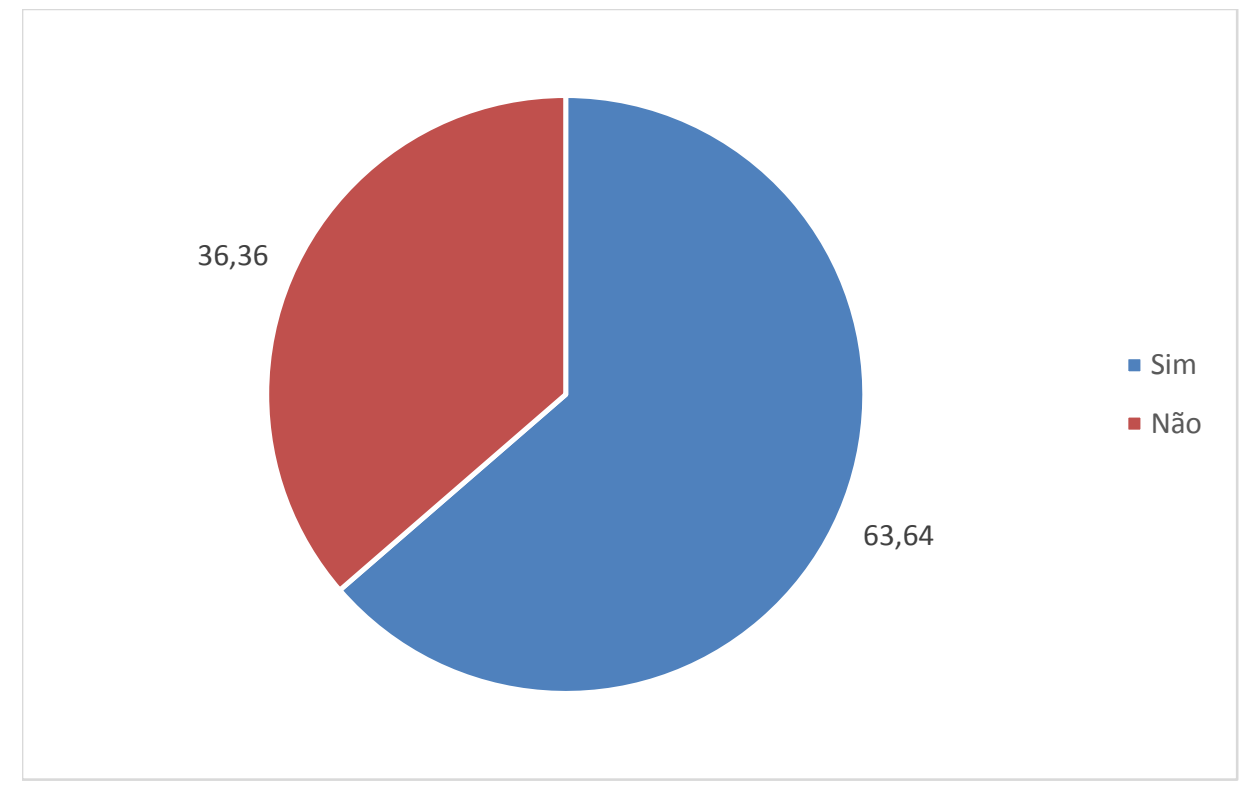

Gráfico 6- Banda - Músico na família

Com relação a pergunta (c), se havia algum músico na família, 63,64\% dos alunos da banda disseram que sim. Quantidade considerável em relação a minoria de $36,36 \%$ que disseram não haver.

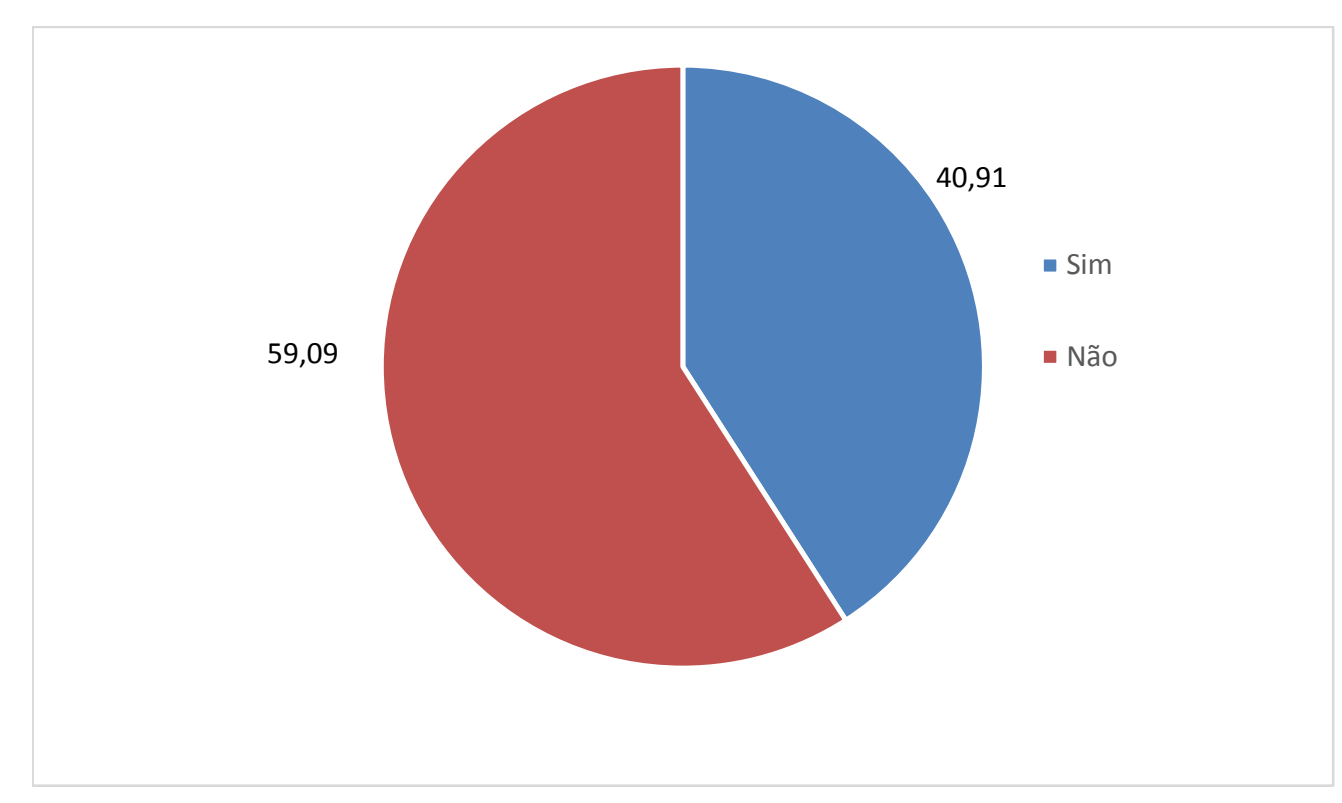

Gráfico 7- Orquestra - Músico na família

Já entre os alunos da orquestra, 59,09\% disseram que não há músico na família, e 40,91\%, disseram que sim. 

nas Escolas. R. Cientifica UBM - Barra Mansa (RJ), ano XXII, v. 19, n. 37, 2. Sem. 2017. p. 123-139.

O Projeto Música nas Escolas há 14 anos tem servido como principal formador de músicos profissionais ou amadores na região. Provavelmente este seja o resultado do trabalho realizado durante este período. Porém, para uma afirmação mais concreta, é necessário que se realize uma pesquisa ampla, o que não é o objetivo deste artigo.

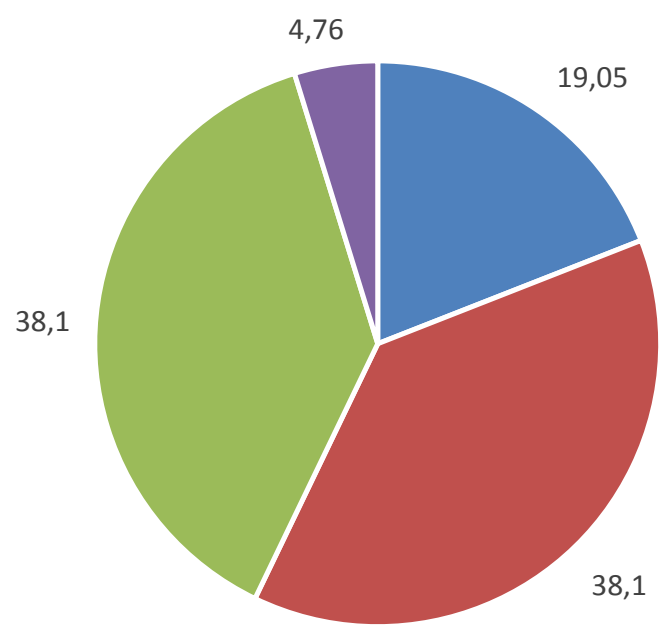

- Entre 1 e 2 anos

- Entre 3 e 4 anos

- Entre 5 e 6 anos

- Não responderam

Gráfico 8- Anos de estudo de música - Banda

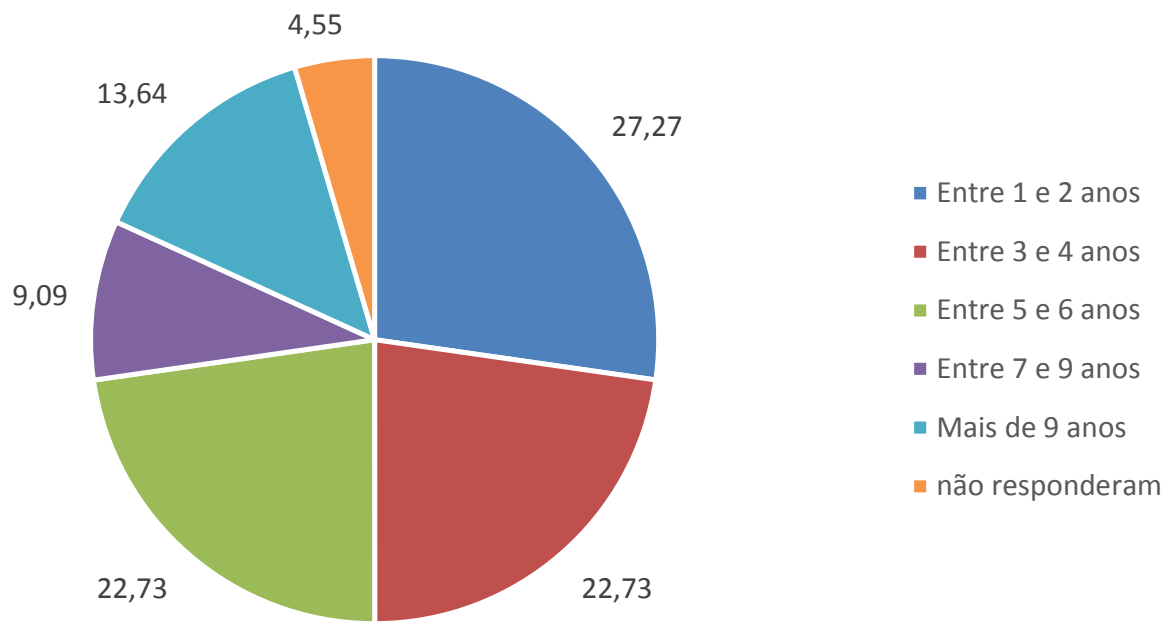

Gráfico 9- Orquestra - Tempo de Estudo

O tempo de estudo do instrumento vaia muito de um grupo para outro. $\mathrm{Na}$ banda, 19,05\% dos componentes estudam música há cerca de dois anos. Entre três e 
quatro anos de estudo, 38,10\%, também outro grupo, com 38,10\% estuda música entre cinco e seis anos. Destes, 4,76\% não respondeu.

$\mathrm{Na}$ orquestra, o aluno que tem menos tempo de estudo de música dista do que tem mais tempo de treze anos. Até dois anos de estudo são, 27,27\% dos alunos; entre três e quatro anos, e cinco e seis anos, ambos os grupos formam 22,75\%; entre sete e oito anos de estudo, 9,09\%; mais de nove anos de estudo de música, 13,64\%.

Segundo a informação da gerência pedagógica, não há seleção previa para quem deseja ingressar em um dos grupos musicais do P.M.E.B.M. Esta afirmação é confirmada pelos maestros. De acordo com os maestros, por este motivo, existe certo desnivelamento entre os componentes, o que as vezes dificulta nos ensaios.
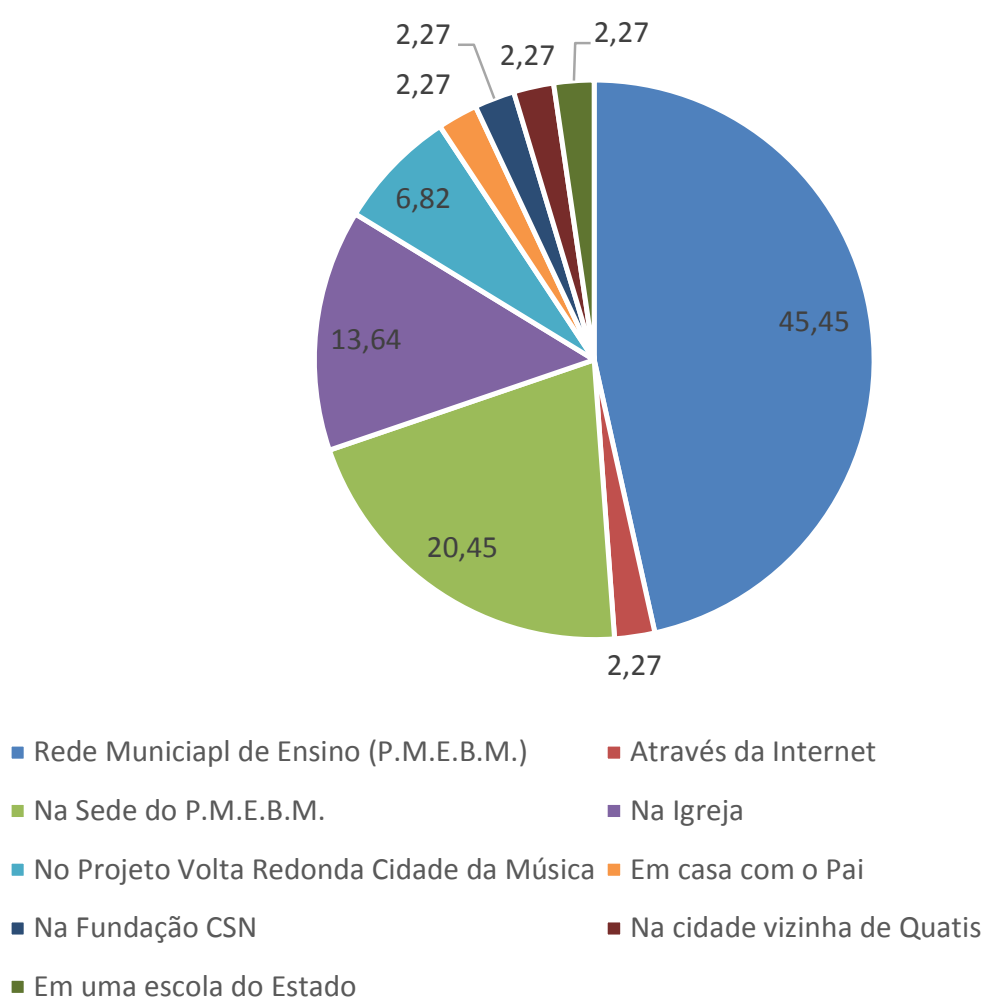

Gráfico 10- Banda - Onde iniciaram os estudos de música

Embora a maioria dos alunos da banda e da orquestra tenham iniciado seu estudo de música no P.M.E.B.M, uma parcela considerável teve sua iniciação ao instrumento em outros locais. Do total, uma média de $60 \%$ começou a estudar de música no P.M.E.B.M. Em ambos os grupos, 45,45\% dos alunos tiveram sua iniciação 
nas escolas da rede pública de Barra Mansa. Outra parcela significativa 20,45\% dos músicos da banda, tiveram a iniciação diretamente na sede do P.M.E.B.M. Na orquestra, foram $18,18 \%$ dos integrantes.

As igrejas, não especificando denominações ou credos, também contribuíram para a iniciação musical dos componentes tanto da banda quanto da Orquestra. Em ambos os casos a parcela de iniciados em igrejas foi de 13,64\%.

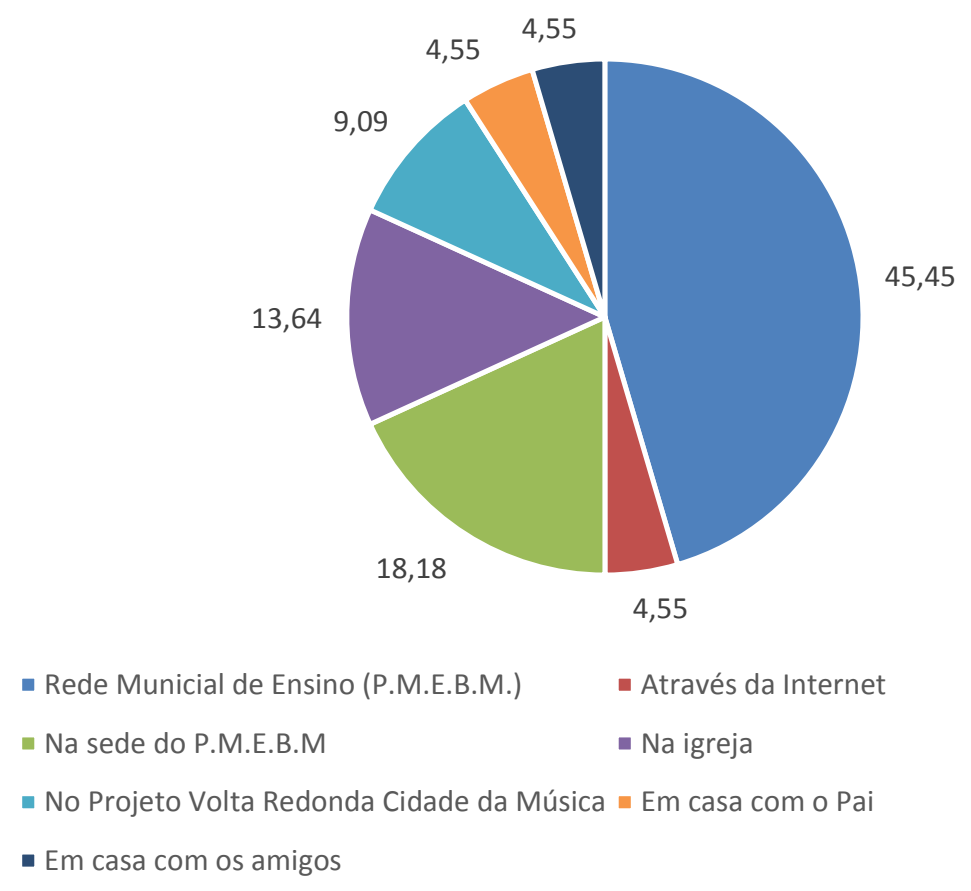

Gráfico 11 - Orquestra - Onde iniciou os estudos musicais

Podemos classificar como formal e informal a iniciação dos alunos do projeto que integram a banda e a orquestra. Formal uma educação musical escolar, oficial, ou dotado de uma organização, e informal, onde os conhecimentos são partilhados em meio a uma interação sociocultural (GASPAR, 2007; SAVIANI, 1989; WILLE, 2005).

O Projeto Música nas escolas também tem alunos oriundos de outras instituições que promovem o ensino formal de música na região. Dos alunos que disseram ter se iniciado em projetos similares, a maior parte é oriunda do Projeto Volta Redonda Cidade da Música, no município vizinho. De lá, vieram 6,82\% dos alunos da banda e 9,09\% da orquestra. Outro projeto mencionado, foi o da Fundação CSN, também na cidade de Volta Redonda, no qual 2,27\%. 
Outros alunos tiveram sua iniciação informal sendo com amigos, 2,27\% da banda e 4,55\% orquestra; sozinho, através de métodos, $2,27 \%$ banda; com o pai $4,55 \%$ orquestra; através da internet $2,27 \%$ da banda e 4,55\% da orquestra; outros 2,27\%.

O alcance do Projeto Música nas Escolas é bastante abrangente. Embora seja destinado a alunos da Rede Pública Municipal de Ensino, tem atraído pessoas de toda a região.

Todos os alunos do primeiro seguimento do ensino fundamental têm aulas de musicalização e canto coral na Escola. Os alunos do primeiro ao terceiro ano podem participar de aulas opcionais de pífaro e percussão, que os prepara para a prática de outros instrumentos.

Quanto ao fato de alunos oriundos de outras entidades também que procuram diretamente a sede do projeto, o maestro da orquestra ressaltou que de certa forma há uma ruptura no processo de ensino de instrumento.

O projeto cultiva em seus grupos um repertório variado, conforme pode ser observado em programas de concertos. A OSBM, por exemplo, realiza na temporada anual, dez concertos oficiais, e vários outros na periferia e em outras cidades.

Tanto a banda como a orquestra são grupos formados basicamente por adolescentes. Procuramos então saber quais os gêneros musicais preferidos dos integrantes, e se o tipo de repertório dos grupos influencia de certa forma seu gosto musical.

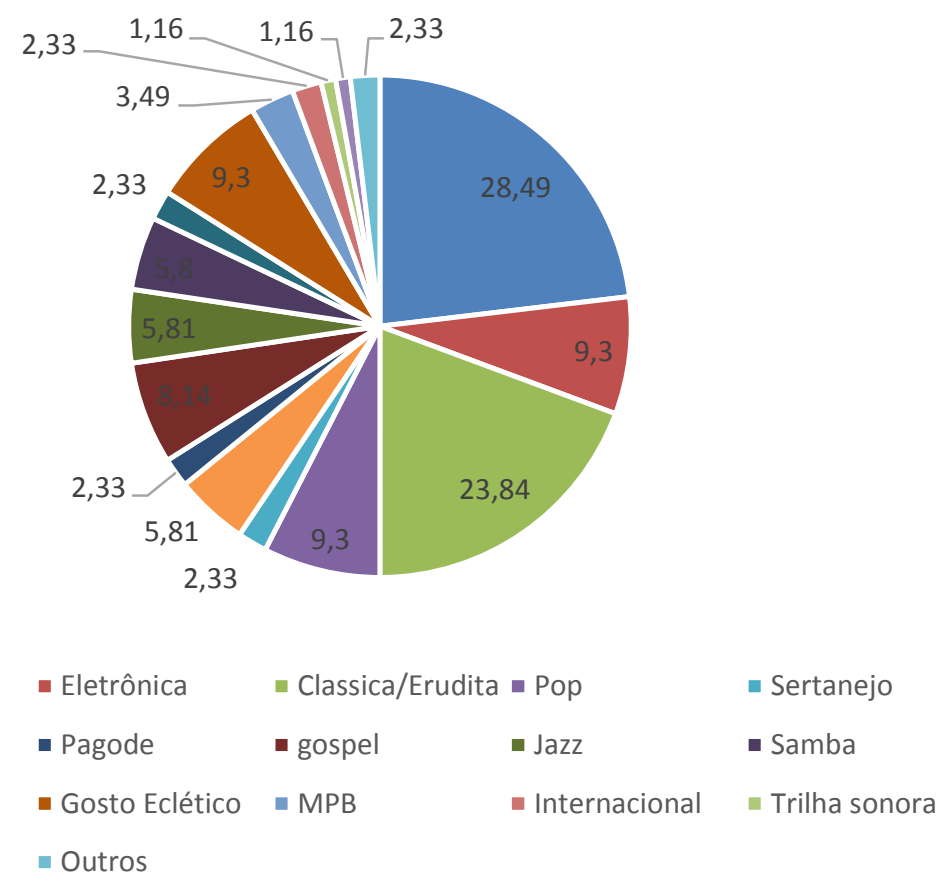

Gráfico 12 - Banda e Orquestra gêneros musicais preferidos 
Segundo a pesquisa, percebemos que é grande a diversidade de gêneros musicais que definem o gosto pessoal dos adolescentes da banda e da orquestra. A preferência assinalada no gráfico acima, resultou da quantidade de vezes que um gênero foi mencionado, com os integrantes dos dois grupos.

Do total de gêneros mencionados, o preferido da maioria dos adolescentes dos dois grupos foi o rock, com 28,49\%; em segundo o gênero preferido entre os alunos foi a música clássica/erudita, com 23,84\%. A música eletrônica, MPB e pagode, vem em seguida com 9,30\% da preferência. Outros gêneros citados foram: música gospel, com suas variantes, 8,14\%; o jazz, e também o samba, com 5,8\%; e música pop com 3,14\% dentre outros.

Com relação à preferência por gêneros musicais, Tavares (2012), apud Meyer (1963), afirma que

[...] pode ser definida como a predileção ou eleição determinada por algo. Tratando-se de música, as preferências podem ser estabelecidas tanto de maneira autônoma, a partir da eleição consciente do indivíduo do que quer escutar em seu cotidiano, como de modo induzido, a partir da escuta involuntária por imposição do meio ou por influência de outros. (TAVARES, 2012, p.199)

Em pesquisa realizada sobre os gostos musicais de adolescentes, e a variedade de músicas que ouvem, Soares (2012) afirma que ela advém da facilidade e grande diversidade de estilos disponibilizada pelas tecnologias de reprodução. Para o autor,

Os gostos musicais desses adolescentes além de constituírem-se como um repertório compartilhado por indivíduos de um mesmo grupo, forma entre estes, laços de identidades cuja cultura só faz sentido para o grupo quando vivida no cotidiano (SOARES, 2012, p. 22).

Para Monte et al. (2012, p.2), a aquisição de determinado gênero ao gosto pessoal, tem uma certa ligação a exposição do indivíduo a algo novo, e como exemplo, citou a música "erudita ocidental".

Durante pesquisa realizada em uma escola especializada de música, Monte (2012, et. al.) concluiu que os alunos "entrevistados notaram uma mudança sutil ou significativa em sua apreciação musical, que é a aquisição de novas músicas ao seu "ouvir cotidiano", em virtude da vivência do novo repertório" (MONTE et. al. 2012, p. 2) 
Outro fato notado por Monte et al. (2012) foi que "o gosto musical dos sujeitos foi ampliado, mas não sofreu alterações nas apreciações anteriores. Compreendeu-se, portanto "que os sujeitos, tendo escolha definida ou não, ampliaram as possibilidades de gosto musical”. (MONTE et. al., 2012, p.4).

É interessante notar que dentre os gêneros musicais mais apreciados está a música de concerto, mencionada por eles como música clássica, corroborando com a afirmação de Monte et al. (2012) de que o gosto surge através da exposição e do ouvir, uma vez que este tipo de música é divulgado pelos meios de comunicação.

\section{Considerações Finais}

Barra Mansa é um município com 171.125 habitantes. O Projeto Música nas Escolas tem alcançado cerca de 22.500 alunos com aulas de musicalização, canto coral e prática de instrumentos musicais, e musicalização infantil. Com isso, foram criados diversos grupos musicais, como bandas, orquestras, corais, quartetos, quintetos, dentre tantos.

O Projeto Música nas Escolas de Barra Mansa tem impactado de forma direta o ensino de música no município, e também, indiretamente, cidades circunvizinhas, já que alunos oriundos de outras localidades têm procurado a cidade para o aprendizado de um instrumento. Vários músicos que passaram pelo projeto hoje trabalham profissionalmente em diversas orquestra e bandas pelo país. Muitos também se tornaram músicos amadores, tocando em igrejas, festas ou outras atividades em suas comunidades. Destes, muitos foram integrantes da Banda Sinfônica ou da Orquestra Juvenis de Barra Mansa.

Neste artigo procuramos conhecer o perfil dos componentes da banda e da orquestra, grupos formados basicamente por adolescentes alunos do Projeto Música nas Escolas de Barra Mansa, e também por pessoas de vários outros projetos da região que buscando o aprendizado de um instrumento.

O Projeto Música nas Escolas de Barra Mansa é uma iniciativa que deu certo, muito relevante para a sociedade barra-mansense, e pode ser um modelo a reproduzido por outros municípios do Brasil. 


\section{Referências}

ALVARES, Sérgio Luís de Almeida; GONÇALVES, Eliete Vasconcelos;

COROPOS, Mônica; COSTA, João Daniel Cardoso da; SILVA, Gabriela Salgado

Coelho da; SOUZA JÚNIOR, Vantoil de; VOIOLA, Daniele. Desafios, motivações e possibilidades de um grupo de educadores musicais brasileiros sob a perspectiva da Musicalidade Abrangente. Anais... XXI Seminário Latino-americano de Educação Musical. Meio eletrônico, 2015. Disponível em:

<http://www.fladem.info/whats_new.html> acesso em: 18 jan. 2016

ARROYO, Margarete. Transitando entre o "Formal" e o "Informal": um relato sobre a formação de educadores musicais. In: Anais... Simpósio Paranaense de Educação. 7. Londrina, 2000. p. 77-90.

GASPAR, Alberto. A educação formal e a educação informal em ciências. Meio Eletrônico. pp. 171-183. Disponível em:

<http://www.casadaciencia.ufrj.br/Publicacoes/terraincognita/cienciaepublico/artigos/ar t14_aeducacaoformal.pdf. > Acesso em: 25 fev. 2017.

MONTE, Gessyane de Santana; ARAÚJO, Valquíria Freitas de Vasconcelos; GOMES, Victor Hugo Almeida; SILVA, Marco Antonio. A influência do repertório do ensino coletivo para instrumentos de cordas no gosto musical dos graduandos da UFC. In: Anais... IV Encontro Universitário da Universidade Federal do Ceará. Juazeiro do Norte, 2012. Disponível em: <http://conferencias.ufca.edu.br/index.php/encontrosuniversitarios/eu-2012/paper/viewFile/844/692>Acesso em 20 mar. 2017.

SAVIANI, Demerval. Tendências e correntes da educação brasileira. In Mendes, Durmeval Trigueiro (Org.). Filosofia da Educação Brasileira. São Paulo: Civilização Brasileira, 1994.

SOARES, Edna Andrade. O Adolescente e o Rock: a preferência musical como uma atividade reflexiva. In: Anais... VII Encontro Regional Norte da ABEM Educação Musical em Perspectiva: Tecnologia, Inovação e Inclusão pp. 20-28. Belém 2012. Disponível em: $<$ http://www.abemeducacaomusical.com.br/sistemas/anais/congressos/ANAIS_VII_AB EM_REGIONAL_NORTE_BELEM_PA_2012.pdf> acesso em 13 mai. 2017. 
TAVARES, Lucilene Aparecida Santos. A Influência das mídias nas preferências musicais dos alunos da Escola Estadual Coronel Filomeno Ribeiro: Um relato de experiência. In: Anais... VII Encontro Regional Norte da ABEM: Belém, 2012. Disponível em:

$<\mathrm{http}: / /$ www.abemeducacaomusical.com.br/sistemas/anais/congressos/ANAIS_VII_AB EM_REGIONAL_NORTE_BELEM_PA_2012.pdf> Acesso em: 13 abr. 2017.

WILLE, Regiana Blank. Educação musical formal, não formal ou informal: um estudo sobre processos de ensino e aprendizagem musical de adolescentes. Revista da ABEM, Porto Alegre, V. 13, 39-48, set. 2005. 